\title{
EXPLORING THE COMBINED USE OF SOLICITED DIARIES AND PHOTOGRAPHY BY OLDER PATIENTS IN THEIR PROCESS OF SELF-CARE WITH MEDICATION PACKAGING
}

\author{
Carli Lorenzini, Giana; \\ Olsson, Annika \\ Packaging Logistics, Department of Design Sciences, Lund University
}

\begin{abstract}
Design has the potential to include or exclude people, depending on how user needs are translated into products. Design exclusion has been vast in design for health care. Medication packaging design is a common example. It does a good job of protecting the product but can result in creating difficulties when used, especially for those who are older. Research in this area lacks an inclusive and usercentered approach because potential users have been studied outside of their context of living and with methods that limit participation. The aim of this study was to explore the combined use of solicited diaries and photography to engage and include older users in gathering data and reflecting on their day-to-day experiences of using multiple medications and the medication packaging. Our findings show key learnings of using this combined method, as well as related methodological challenges, and provide recommendations to tackle these challenges. The use of solicited diaries with photographs taken by participants is deemed to be relevant in interdisciplinary fields of research and practice, where designers and other professionals aim to better understand the reality of older people and create meaning in their experiences of self-care.
\end{abstract}

Keywords: Design methods, Inclusive design, Medication packaging, Patient centred design, User centred design

\author{
Contact: \\ Carli Lorenzini, Giana \\ Lund University \\ Design Sciences \\ Sweden \\ giana.lorenzini@plog.lth.se
}

Cite this article: Carli Lorenzini, G., Olsson, A. (2021) 'Exploring the Combined Use of Solicited Diaries and Photography by Older Patients in Their Process of Self-Care with Medication Packaging', in Proceedings of the International Conference on Engineering Design (ICED21), Gothenburg, Sweden, 16-20 August 2021. DOI:10.1017/ pds. 2021.412 


\section{INTRODUCTION}

Multiple advances in medicine, combined with changes in lifestyles, have led to an increase in life expectancy (Huijg et al., 2017). By 2050, it is estimated that more than 2 billion people will be 60 years of age or over, with about 400 million of them being 80 or older (WHO, 2012; Age International, 2020). Longevity has impacted with a shift towards self-care in home environments (Marek and Rantz, 2000). This shift has increased the responsibility of older people for their own care, calling attention to the emerging need for design approaches to improve the way health care products are designed.

Design is generally regarded as an interdisciplinary field of knowledge that seeks for better understanding of users and their contexts of use. Hence, it is not surprising to see a growing interest in design research coupled with health and social sciences research (Morrison and Dearden, 2013). Yet, many health care products have been traditionally designed following a product-centric approach, omitting user perspectives, resulting in design exclusion of older populations. Very often design exclusion occurs when the expert view prevails, where designers "instinctively design for their own capabilities and skills" and, thus fail to identify and translate end-user information into inclusive usercentered design concepts (Keates and Clarkson, 2003, p. 224). Design exclusion can perpetuate when the expert view is not challenged by design approaches and methods that allow participants to speak for themselves and to become engaged in their participation throughout the study (Visser et al., 2007). One area where design exclusion has become evident for decades is in medication packaging design. Medication packaging has been designed with a great focus on protection of the medicine but not always with consideration of user needs (De La Fuente and Bix, 2011). Surprisingly, research in this field has been limited to understanding the technological aspects of medical packaging and the interaction that exists between people and packaging in situations where participants are not in their home environments (Lorenzini and Hellström, 2017). Emphasis has been put on the functional challenges packaging design creates, with recurrent studies engaging participants in test settings that report difficulties with open/close closures as well as problems with instructions on the packaging (e.g., Sormunen et al., 2014). To a lesser extent, design researchers have explored other qualitative methods to understand human-packaging interaction in daily routines and the users' experiences with medication packaging outside of laboratory facilities (Ward et al., 2010).

Departing from the example of medication packaging, this study explores the combined use of solicited diaries and photography to engage and include older people in gathering data and reflecting about their day-to-day experiences of using multiple medications and their packaging. The importance of a combined qualitative method like this is not only to inform design professionals on how to better design health care products, such as medication packaging; it is also to create evidence for a human-centered design methodological approach that intends to reduce design exclusion of older populations in the context of self-care. Additionally, we foresee that participatory design research is becoming fundamental in promoting a change from product-centric towards inclusive user-centric design in health care, and ultimately, to fulfill the general sustainable goals of promoting good health and well-being.

\section{BACKGROUND}

Diaries can be unsolicited or solicited. Unsolicited diaries are based on the personal notes taken without the request or guidance of a researcher, mainly for a person's own benefit of self-reflection without intention of someone else reading it (Jacelon and Imperio, 2005). Conversely, solicited diaries are written with a "strong awareness of the researcher", that is, the knowledge that diary entries will be read by the researcher to fill a purpose (Elliott, 1997). Solicited diaries are often seen as most valuable when extended periods of participant observation are not possible nor practical (or would be altered in the presence of a researcher) (Zimmerman and Wieder, 1977). In connection with studies of patient's health, solicited diaries have been used to uncover the reality of patients, especially in considering "symptom identification and management, use of health services, and responses to medical and nursing interventions" (Burman, 1995, p. 151). Solicited diaries seem to be particularly relevant to track symptoms that would otherwise be trivial or that would be difficult to capture (Milligan et al., 2005).

When discussing health issues, solicited diaries can be combined with other data collection methods, such as interviews, in what is called the diary interview method (Zimmerman and Wieder, 1977; Alaszewski, 2006). Typically, the solicited diary is "sandwiched" between interviews: one interview before and another interview after diary completion. Solicited diaries follow the pace of the participant, with more freedom for the respondent to decide what to report and how to report it, 
without an "interactive component in the daily reporting" (Rosner et al., 1992, p. 263). Interviews, on the other hand, are mostly based on the pace and interactive guidance of the interviewer. For older patients, interviews about their health conditions can also be seen "as a social visit, an unhurried opportunity to talk about themselves to an interested listener", taking on "the feeling of conversation" (ibid.). The combination of methods permits researchers to gain access to a richer understanding of the health conditions and contexts in which patients live, as well as the process of decision-making about their ongoing routines.

In contrast to the traditional use of solicited diaries, researchers have started to explore modifications of the diary interview method, adding to it other resources such as photography. Barlett (2012, p. 1718), for instance, sees that it is beneficial to give diarists alternative tools that give them control in selecting "what they want to express and how they want to express" themselves about their lives. An example is to give participants a camera to photograph what they see as relevant. Photo elicitation the use of photography in research to elicit information from participants - helps participants to remember events when talking about them, evoking "deeper elements of human consciousness" than when only using words (Harper, 2002, p. 13). According to Kantrowitz-Gordon and Vandermause (2016), photo elicitation helps the teller create a meaningful life narrative of daily events, as well as helps the viewer (i.e., the researcher) to become acquainted with unfamiliar experiences. In combination with interviews, participants have time to reflect on the meaning depicted in the photograph and the choices made about the subject photographed.

\section{RESEARCH DESIGN}

The study follows a qualitative research design. We selected older people with chronic diseases who are using multiple medications daily. The participants were asked to reflect on their own well-being and, specifically, report their experiences with medical packaging in a solicited diary filled with personal notes and photos for a week. The study was approved by The Swedish Ethical Review Authority.

\subsection{Participant selection}

An invitation letter was sent out to several senior and patient associations in southern Sweden. One researcher also visited facilities where older people gather for educational and recreational activities. At these places, the researcher distributed the invitation letter and explained the study. Those interested registered by providing their contact details, or by directly contacting one of the researchers via email or telephone. The inclusion criteria were: 65 years of age or older at the time of the study, use of three or more different medications on a daily basis, interest in taking pictures and completing a diary for one week. New participants were added to the study until response saturation was reached (Flick, 2014).

In total, fifteen respondents were enrolled in the study ( 10 females, 5 males). The mean age was 76.2 years, with a range between 65 and 88 years. Eleven respondents lived in a house or apartment with a partner, whereas four participants were living alone. None of them received external care to help sort out their medications. Ten respondents used up to seven different medications every day, whereas five respondents had up to fifteen daily medications. For many patients, medication has been part of their lives for many years, with twelve participants reporting the use of at least one medicine for a chronic condition for over a decade. Other medications were added to their treatment over the years.

\subsection{Data collection}

Based on recommendations from previous research, we used the diary interview method combined with photo elicitation. Data collection started with one initial interview, followed by the week-long diary completion, and then a follow-up interview to retrieve the diary and discuss the process of writing it and taking the pictures. As indicated by other researchers, it is advisable to limit the time for diary completion, preferably no longer than two weeks (Jacelon and Imperio, 2005). We conducted a pilot study with one participant to test the interview guide and diary instructions. Seven days seemed to be the ideal time for the completion of the diary with notes and pictures. Amendments were made to the interview guide and the instructions on completion of the diary.

The initial face-to-face interview was arranged either at the home of the participant or at the university facilities with one researcher. The participant received additional information about the study and answered semi-structured questions, for instance, about their living conditions, their history of using the medications and their daily routines for taking them. At the end of the interview, participants were 
also informed about the diary-keeping process and were given a demonstration on how to operate the instant photo camera. Each participant received a kit containing: one instant photo camera filled with film to take pictures of the medication and their routines in following their prescribed treatment; one step-by-step manual with instructions about how to operate the instant photo camera; a glue stick; a copy of the signed consent form; and a diary. The diary was composed of one cover page and seven double-sided A4 sheet with question prompts and a space to paste one picture for each day. One double-sided A4 sheet was to be filled per day for a total of seven consecutive days (Figure 1).

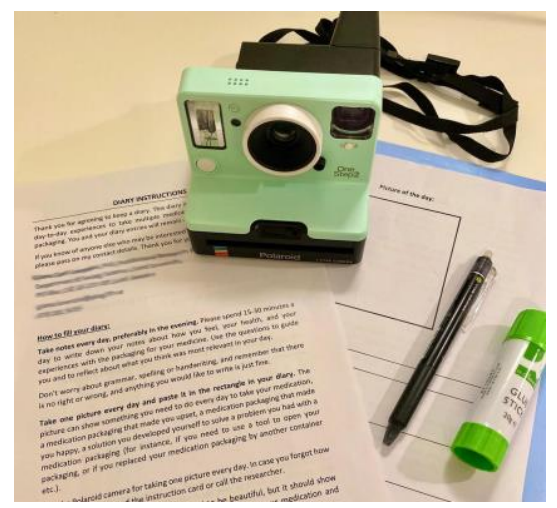

Figure 1: Diary kit provided to each participant.

A follow-up interview was booked within three weeks. The purpose of this post-diary interview was threefold, as suggested by Barlett (2012): a) to collect the diary, b) to ask participants about their experience of completing the diary, the general feelings associated with writing it daily, the identification of any problems with the structure and presentation of the diary, c) to discuss additional personal entries in the diary. One researcher and the diarist looked together at each page of the diary containing a picture and the corresponding notes. The participant could explain the picture and the general memories of that day. All the interviews were audio recorded and transcribed verbatim.

\subsection{Data analysis}

The data were analyzed through qualitative thematic analysis (Braun and Clarke, 2006). First, all interview transcripts were imported and stored in a qualitative data analysis software (Nvivo, QSR International), where they were read entirely at least once, and initial themes were created. At a subsequent reading, relevant segments of the text were marked and moved into emerging themes. As the analysis progressed, the themes were refined and segments of text were regrouped accordingly. One researcher was mainly responsible for the thematic analysis, whereas the themes and coding were reflectively discussed with another senior researcher. A spreadsheet was created with the themes and a short description of each one. Subsequently, all photos were scanned digitally. Notes from the diaries were typed into one spreadsheet. Photos and their respective notes were analyzed together and grouped into themes using the coding scheme from the interviews. This allowed for more thematic iterations and further refinements until reaching consistency within each theme. At the end, the main themes were identified in relation to the experiences reported by the participants. Notably, the photos and verbal explanations helped participants to articulate their tacit knowledge, whereas the multiple methods of data collection and the pre- and post-checks between the participants and researchers enhanced the data quality and validity, ultimately leading to trustworthiness in the research process (Glegg, 2019).

\section{FINDINGS}

This section presents the key findings of combining the diary interview method with photo elicitation for the purpose of engaging older patients in inclusive design research in this study of medication packaging and self-care. The names of participants have been changed to protect user privacy.

\subsection{Purposefulness in writing a solicited diary - a work task for supporting research}

By presenting blank diary pages with question prompts and a camera to take photos, participants were given the autonomy to depict their own narratives in the diary. Yet, not all the participants had the same purposefulness for writing a solicited diary. As Martin stated, he saw the diary "as a little work 
task to be completed, and that you [the researcher] should enjoy your research". Others thought about the researcher who would be reading it and thus tried to write neatly so that the researcher could understand the handwriting as well as their thoughts behind the notes taken. Maria, for instance, asked: "Why else would I write this [the diary] if no one is going to read it?". Similarly, Karla also commented by asking herself several times: "What do they want with this answer?"; "What is important here?". Another participant wrote in her diary that maybe she was not very good in finding problems with medication packaging, which also revealed concern about meeting the research purpose of the diary. On the other hand, some participants mentioned that they simply filled in the diary without thinking much about who else would read it, with "a pretty empty heart" as one participant, Philip, stated. Others commented that they just reported objectively what happened or what they thought about it.

Curiously, five of the participants mentioned having an unsolicited diary in which they report facts of their lives or experiences of their treatment on a continuous basis either on paper or on a computer. Unlike the solicited diary in this research, the unsolicited diary was sometimes used as a source for discussion with the participant's partner or family, as a piece of documented memory.

\subsection{The routine of writing a solicited diary - embedded in medication routines}

In general, all the participants had a very clear routine for taking their medications and were quite engaged in the maintenance of their well-being. Thus, it was not surprising that writing the diary about their medication became an activity embedded in their daily routine. When asked about the experience of writing the diary, the respondents reported that the instructions and questions were easy to follow. Peter commented: "It was nice and easy [to complete the diary]. There were no problems. I just had ideas and suggestions for seven days". This probably shows he had thought about planning his diary according to the timeframe the researchers gave him. Likewise, Susanne said: "It was only a week, so really nothing at all. If it had been three months, one could complain about it". One participant particularly enjoyed having the pictures associated with the text, as he explained:

It was very educational and easy to do. No problem. And so, with the help of the Polaroid we got some documentation. It is always good when you can combine text and image. It is easier to make this association and combine. A picture says more than a thousand words. [Martin, 83]

Still, the diarists mentioned several times that there was little variation in their answers from day to day, as life mostly went along as usual. Some respondents felt that the process was repetitive with the same questions to answer for seven consecutive days. This was also perceptible in the progression of this kind of note taking, with short answers to certain questions and repetition. By the end of the week, it was common to see that the diarists were out of ideas about what to write, as one expressed:

It went well for three days, then I thought 'aff, should I do that again?', It was because I'd grown tired of the repetition. Doing the same thing every day. The diary asks how I am and so on, and if nothing dramatic happens, you [the researcher] just get 'no, okay, well' [...]. [Karla, 76]

No participant reported any problems in operating the camera, but some complained about the limited quality of the printed pictures. The instant camera did not take high-resolution pictures and it had limited features for close-ups with small details. To cope with that, two participants actively decided to take pictures with their own mobile phone instead and print it at home. Two others also included some pictures that where not taken with the instant camera.

\subsection{Perceptions about one's own health and treatment - enhancing reflections on personal feelings and capabilities}

The process of note taking in combination with the photography helped participants to narrate some of their main frustrations in using multiple medication and their packaging. This process also enlightened what the writer meant with the photo he or she had taken, which would otherwise be inaccessible to the researcher. Josephine, for instance, took a picture of two of her vitamin bottles and wrote: "I wish I only needed to take these pills". Without this note, the photo only showed two white plastic bottles of vitamins. She added in her diary: "I hadn't thought that health was the most important thing in life before my stroke", revealing self-awareness not only about how her health had changed after her stroke, but how her entire life had changed. Later in the follow-up interview, she added: "You take it 
for granted when you are healthy [...], that life should be like that. You don't think with gratitude 'oh, how nice that I am healthy'. You should put more value on it" (Figure 2).
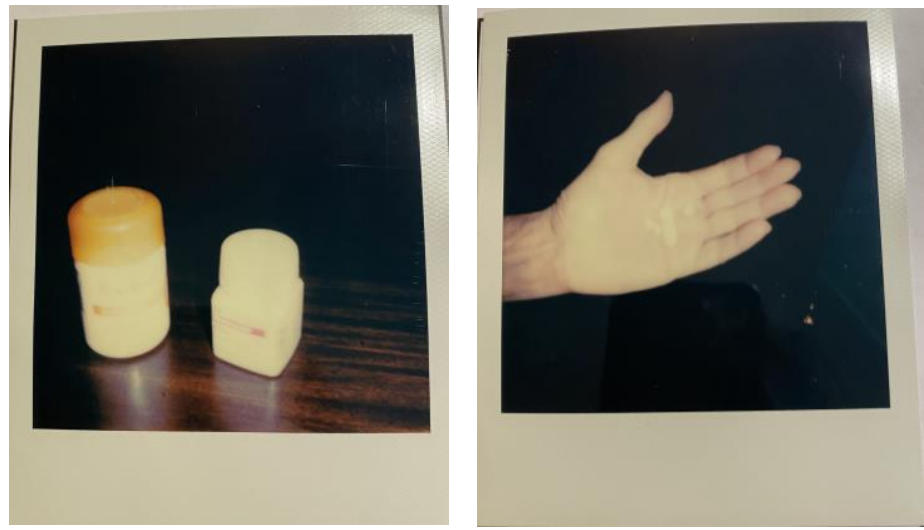

Figure 2: On the left: "I wish I only needed to take these pills". On the right: "How much I don't like taking medications, but I have to" [Josephine, 76].

Moreover, it was noted that when asked in their diaries, "How do you feel today?", the participants had at times episodes where a disturbance in their treatment or a problem with their medication impacted their general well-being. The feeling of distress could remain for days until a solution was found, and routines were stabilized again. Such episodes would be difficult to capture with an interview only. In the diaries, some participants reflected on the distressful experience, how it affected them, and how they found the solution (with or without the help of others). However, for other diarists, answering "How do you feel today?" was a broad question not always easy to verbalize nor distinguish from the ordinary answers that one usually gives when this question is posed.

When reflecting about their own health, participants showed empathy with other older people living with chronic conditions, who also need to manage several medications a day. For instance, Josephine said: "Now my husband can help me, and I'm not that old, but I think of those who are even older and even weaker and who live by themselves". Similarly, another participant commented:

I am not the weakest. There are many at my age that are much worse. If you have less strength [in the hands, to open the medication packaging]; and most of the people at my age take a lot of medications. Why do they do it like that? ["they" refers to the companies producing the packaging] [Sylvia, 83].

\subsection{Self-expression and deviation in the solicited diaries and photos - from medication to lived experiences}

In the instructions given, participants were asked to photograph their routines with their treatments, and the daily use of medication packaging. Even though most of the participants objectively followed the instructions and answered what was asked in the guiding questions, a few participants stood out using creative means that deviated from the instructions, finding new ways of expressing themselves. For instance, Sylvia took a self-portrait as the final picture of her seven-day diary. In the description she added: "Me. 83 years old and capable of taking care of our household without help. So why do I need help with medication packaging?". For her, it was important to use this self-portrait as a statement of how she perceived herself, and how disconnected from her self-image the medication packaging with difficult designs was. Sylvia mentioned that writing the diary was good: "One can think about other things than just tablets, one can think beyond that, I think".

A few participants deviated from the main thematic of the solicited diaries by illustrating joyful moments they experienced during the week (Figure 3). Annette, for instance, chose to use other images rather than pictures of medication when something positive happened that day: a bouquet of flowers, because it was her birthday and wrote: "There is life after all", a bus to show a one-day trip with friends, a cartoon symbolizing her involvement with a Parkinson's patient group, a group of students working together. Alba had a picture of running shoes, where she explained she did not manage to exercise because of the side effects of her medication, and she wrote: "How sad it is to not be able to train". Later in the week, she pasted an image of a bicycle and commented: 
I took this picture because I have been improving my balance with a physiotherapist, and today I dared to go for a bike ride. It's good. It's healthy. What freedom and how nice it is to ride a bike! I can deal with the possible problems I may have with the medications later on. For now, I am a happy cyclist and newly retiree [Alba, 67].
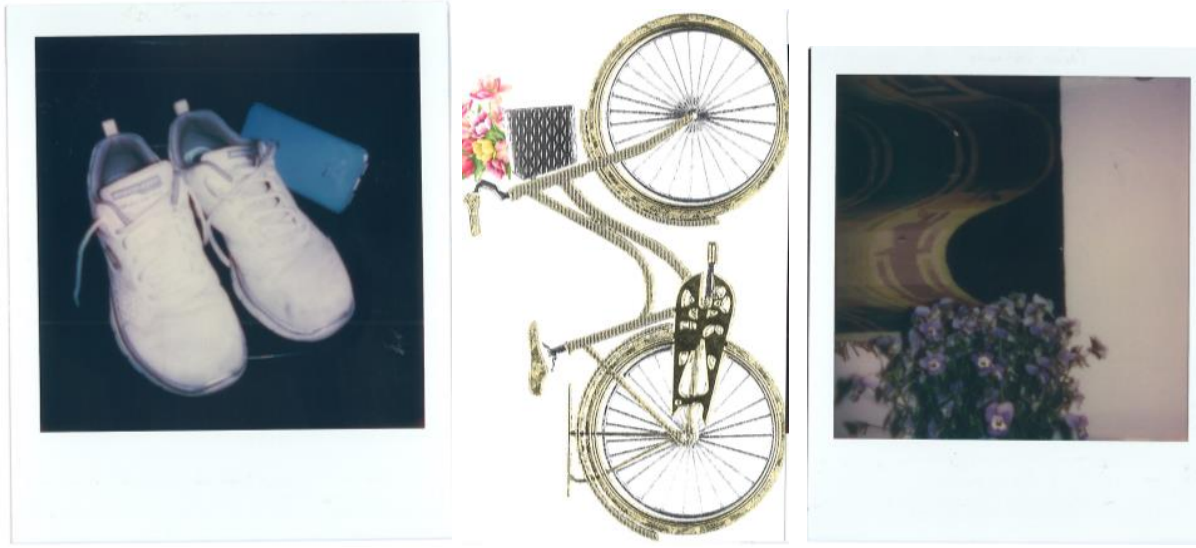

Figure 3: Photos from diarists about lived experiences.

\section{DISCUSSION ABOUT METHODOLOGICAL CONSIDERATIONS}

Throughout our study, we came across a series of fruitful learnings that showed the advantages of using the combined methods. In parallel with these key learnings, methodological challenges also arose, something that design researchers need to be aware of. Recommendations to address the challenges are summarized in Table 1.

Solicited diaries are, in essence, written with an intention in which participants end up doing it for someone else - in this case, the researcher. As affirmed by Xie et al. (2012, p. 414): "Older adults may feel marginalized due to changes in family, careers, and physical and mental health. Therefore, design methods must enable them to understand that they have something important to contribute and that they have the capability to (continue to) make important contributions in later life".

In our study, we learned that the participants sensed they were contributing to research that could lead to change in the way medication packaging is designed, not only for themselves, but for fellow patients that struggle with their treatments. Most of our participants were engaged in advocating for a change, but there were a few who questioned what kind of answers were expected from them, and others who lost interest after a few days of answering the same questions. We know that not all older people might have the same engagement with treatment that our participants had, and we are aware that our participants are not a representative sample of their age group. It became evident, though, that a certain monotony in the diary process can lead to a decreased sense of purpose and engagement over time. In comparison with other studies, we also had limited the number of participants who were accustomed to keeping a personal diary, unlike other researchers who found that diarists enjoyed the discipline of writing a diary (Barlett, 2012). Thus, it is important (and challenging) to assure that participants find a sense of purpose in the task they are assigned, and that they feel they own their diary process to achieve a deeper level of insights that otherwise would be impossible for the researcher to retrieve. The first interview was intended to clarify the purpose of the study and get to know the participants. One recommendation is that researchers make such contact to clarify the research purpose and reinforce the participants' involvement the study (Jacelon and Imperio, 2005).

The solicited diaries in combination with photo elicitation also triggered a process of self-reflection that made visible "the multiple facets of a person's life, not simply those of interest to the researcher" (Barlett, 2012, p. 1724). The reflections expressed by our diarists resembled the ones identified by other researchers (Milligan et al., 2005). We found that listening to older people in their context of living and letting them take photos and write notes to represent themselves can help to avoid pitfalls of designing products that reinforce the stigma around the aging process (Wilkinson and De Angeli, 2014). Design researchers and professionals who decide about the design of health care products may want to confront the binary view of aging, where youth is associated with development and growth, and old age is only related to deterioration of health and deficiency (Dankl, 2017). In the case of older 
people, it can be recurrent that external observers want to see them as frail, dependent, and vulnerable. Design should not be used in a way to reinforce these changes by the way products or packages are designed. On the contrary, design should empower people in their process of aging and self-care.

Table 1. Summary of key learnings, methodological challenges, and recommendations

\begin{tabular}{|c|c|c|}
\hline Summary of key learnings & $\begin{array}{c}\text { Methodological challenges } \\
\text { identified }\end{array}$ & $\begin{array}{r}\text { Recommendations to tackle } \\
\text { methodological challenges }\end{array}$ \\
\hline $\begin{array}{l}\text { Participants may take part in } \\
\text { the research because they want } \\
\text { the design of products to be } \\
\text { changed, but they do not } \\
\text { necessarily share the same } \\
\text { purpose as the researcher. }\end{array}$ & $\begin{array}{l}\text { - Creating a study design that } \\
\text { gives purpose and ownership in } \\
\text { the participation. } \\
\text { - Loss of purpose and } \\
\text { engagement over the time. }\end{array}$ & $\begin{array}{l}\text { - Explain openly the purpose of } \\
\text { the research. } \\
\text { - Make contact to activate } \\
\text { participants in data collection. }\end{array}$ \\
\hline $\begin{array}{l}\text { Solicited diary with photo } \\
\text { elicitation triggers a process of } \\
\text { self-reflection with use of } \\
\text { products and beyond. }\end{array}$ & $\begin{array}{l}\text { - Varied levels of detail in the } \\
\text { entries in the diary. } \\
\text { - Dependent on literacy of } \\
\text { participants to write notes. }\end{array}$ & $\begin{array}{r}\text { - Pre-formatted diary and } \\
\text { prompt questions. } \\
\text { - Post-interview to let } \\
\text { participants articulate their data } \\
\text { inputs and to enhance validity. }\end{array}$ \\
\hline $\begin{array}{l}\text { Participants became } \\
\text { responsible for telling their } \\
\text { own narrative through multiple } \\
\text { sources (personal notes, oral } \\
\text { explanations, photography). }\end{array}$ & $\begin{array}{l}\text { - Extensive, in-depth qualitative } \\
\text { data that are complex to analyze. }\end{array}$ & $\begin{array}{r}\text { - Concise code scheme. } \\
\text { - Consultation with participants } \\
\text { pre- and post-diary completion. } \\
\text { - Consultation with research } \\
\text { peers throughout the } \\
\text { coding process. }\end{array}$ \\
\hline $\begin{array}{l}\text { Participants have more control } \\
\text { and responsibility to gather } \\
\text { data and to decide how to } \\
\text { present the data from their } \\
\text { perspective. }\end{array}$ & $\begin{array}{l}\text { - Loss of focus on the main task. } \\
\text { - Deviations can compromise } \\
\text { data collection. }\end{array}$ & $\begin{array}{r}\text { - Clear instructions. } \\
\text { - Explain how their participation } \\
\text { contributes to the research. } \\
\text { - Pre-formatted diary and } \\
\text { prompt questions. }\end{array}$ \\
\hline $\begin{array}{l}\text { Older people are capable of } \\
\text { using technical gadgets to } \\
\text { collect data and learn from the } \\
\text { research process. }\end{array}$ & $\begin{array}{l}\text { - Technical disturbances can } \\
\text { compromise data collection. } \\
\text { - Technical limitations can } \\
\text { annoy participants and } \\
\text { demotivate them. }\end{array}$ & $\begin{array}{r}\text { - Conduct a pilot study. } \\
\text { - Use intuitive gadgets. } \\
\text { - Provide demonstrations } \\
\text { and instructions. } \\
\text { - Establish contact while data } \\
\text { collection is ongoing. }\end{array}$ \\
\hline
\end{tabular}

Undoubtedly, the combined methods (interviews, photos, personal notes) produced richer data than stand-alone methods, but made it more complex to organize and code all the data in order to find relevant themes. Additionally, we noted that we had some participants with a high level of literacy and with sufficient knowledge about their health and treatment to present insightful reflections. Others also produced notes in their diaries with varied levels of detail. As presented by former research, we saw the value of conducting a follow-up interview in a sensible manner to fill any gaps in the participants' narratives, to clarify points that were briefly explained in the diaries, and to help participants further express their thoughts verbally when it had been hard to explain them in writing (Kenten, 2010). As a result, a recommendation is to look at the entries of each page of the diary together with each participant, asking them to verbalize their intention with each picture to enhance validity when interpreting the data gathered by participants and to reduce the researcher's bias. To guarantee trustworthiness in the research, a concise code scheme needs to be applied. Consultation with research pairs throughout the coding process is also recommended.

Another important lesson learned relates to the transfer of responsibility and control in data collection to participants. By using photo elicitation and diary notes, participants have the power to register with both image and text what they find to be meaningful, but this also creates space for deviation from the research aim. This was true in our study, where participants freely decided to report other information and added pictures that were not related to medication and its packaging, despite the instructions given. All participants were retirees; however, their daily activities varied to a great extent including 
common activities in the home (e.g., gardening, taking care of pets, cooking), visiting friends and family members, participation in association meetings. By deviating from the assigned task, participants presented another side of themselves. We did not see these deviations as a flaw in the process of completing the diary, but rather as a conscious choice of participants to share a broader and intimate part of their lives that was different from the general idea of "being a patient". However, some deviations can compromise the study if the data collected by the participants is totally disconnected and not useful in response to the research questions. To prevent that, a recommendation is to clearly present the instructions, emphasizing the contribution participants can make by following these instructions. The way the diary is designed also matters: pre-formatting and the use of question prompts is recommended. Finally, letting participants collect data by using technical gadgets, such as instant cameras, presents opportunities and challenges. As opposed to research in which older patients used their own cameras (Mansfield and Burton, 2020), we provided instant cameras to our diarists. They had no problems operating the camera, however some were bothered when they failed to take the picture they desired or when they could not improve the quality of the pictures. Our participants found ways to deal with these technical limitations by using their own mobile phones or by further explaining in writing or orally their intentions with the photo. Nevertheless, design researchers should be aware that technical disturbances can interfere or entirely interrupt the collection of data. Bugos et al. (2014, p. 5) wisely commented that "researchers should develop realistic expectations for the technical and artistic strength of participants' photographs". There is a need to balance the simple and intuitive apparatus that laypeople can use with the understanding that simpler technologies may generate some frustration for more advanced users or for participants with higher expectations for their photography presentations.

\section{CONCLUDING REMARKS}

Addressing well-being in aging societies demands interdisciplinary work, where design approaches can contribute to understanding older people, their heterogeneity and the complexities involved in selfcare. We join other researchers who are striving for inclusive approaches and combined methods in design to tackle complex societal challenges. Even though solicited diaries and photo elicitation are not new methods in the social sciences, they are still limited in the interdisciplinary field of design for health care. Our study contributes scholarly knowledge about the use of a combined qualitative methods to avoid tokenistic approaches by letting older people create their own narratives around their experiences of self-care. In practice, the application of such combined methods can contribute to the design of not only inclusive packaging, but other health care products to better suit the lifestyles of older people, and more likely to improve their feelings of confidence in their health treatment. We also expect a study like ours to inspire professionals working in interdisciplinary domains where decisions about health and patients' well-being are distributed among many stakeholders with design and nondesign backgrounds. We did not go as far as to co-design or co-create new medication packaging solutions with the participants, which would achieve higher levels on the ladder of participation, as suggested by scholars (Morrison and Dearden, 2013). Thus, there are great opportunities to do more research where older patients are engaged not only in data gathering but also in co-designing for health care.

\section{ACKNOWLEDGMENTS}

We would like to thank all the participants who agreed to take part in the study. We would also like to thank the Kamprad Family Foundation for the research grants received.

\section{REFERENCES}

Age International. (2020), Global Ageing [online]. Available at: https://www.ageinternational.org.uk/policyresearch/statistics/global-ageing/ (accessed November 2, 2020).

Alaszewski, A. (2006), Using Diaries for Social Research, Sage, London.

Barlett, R. (2012), "Modifying the Diary Interview Method to Research the Lives of People with Dementia", Qualitative Health Research, Vol. 22 No. 12, pp. 1717-1726.

Braun, V. and Clarke, V. (2006), "Using Thematic Analysis in Psychology", Qualitative Research in Psychology, Vol. 3 No. 2, pp. 77-101. 
Bugos, E., Frasso, R., Fitzgerald, E., True, G., Adachi-Mejia, A. M. and Cannuscio, C. (2014), "Practical Guidance and Ethical Considerations for Studies Using Photo-Elicitation Interviews", Preventing Chronic Disease, Vol. 11, pp. 1-9.

Burman, M. (1995), "Health Diaries in Nursing Research and Practice”, Journal of Nursing Scholarship, Vol. 27 No. 2, pp. 147-152.

Dankl, K. (2017), “Design Age: Towards a Participatory Transformation of Images of Ageing”, Design Studies, Vol. 48, pp. 30-42.

De La Fuente, J. and Bix, L. (2011), “A Tool for Designing and Evaluating Packaging for Healthcare Products”, Journal of Patient Compliance, Vol. 1 No. 1, pp. 48-52.

Elliott, H. (1997), "The Use of Diaries in Sociological Research on Health Experience", Sociological Research Online, Vol. 2 No. 2, pp. 38-48.

Flick, U. (2014), The Sage Handbook of Qualitative Data Analysis, Sage, Thousand Oaks.

Glegg, S. M. N. (2019), "Facilitating Interviews in Qualitative Research with Visual Tools: A Typology", Qualitative Health Research, Vol. 29 No. 2, pp. 301-310.

Harper, D. (2002), “Talking about Pictures: A Case for Photo Elicitation”, Visual Studies, Vol. 17 No. 1, pp. 13-26.

Huijg, J. M., Delden, A. E. Q. V., Ouderaa, F. J. G. V. D., Westendorp, R. G. J., Slaets, J. P. J. and Lindenberg, J. (2017), "Being Active, Engaged, and Healthy: Older Persons' Plans and Wishes to Age Successfully", Journals of Gerontology: Psychological Sciences, Vol. 72 No. 2, pp. 228-236.

Jacelon, C. S. and Imperio, K. (2005), "Participant Diaries as a Source of Data in Research with Older Adults", Qualitative Health Research, Vol. 15 No. 7, pp. 991-997.

Kantrowitz-Gordon, I. and Vandermause, R. (2016), "Metaphors of Distress: Photo-Elicitation Enhances a Discourse Analysis of Parents' Accounts”, Qualitative Health Research, Vol. 26 No. 8, pp. 1031-1043.

Keates, S. and Clarkson, P. J. (2003), "Countering Design Exclusion: Bridging the Gap Between Usability and Accessibility", Universal Access in the Information Society, Vol. 2, 215-225.

Lorenzini, G. C. and Hellström, D. (2017), "Medication Packaging and Older Patients: A Systematic Review", Packaging Technology and Science, Vol. 30 No. 8, pp. 525-558.

Mansfield, R., and A. E. Burton. (2020), "Exploring the Meaning of Quality of Life for Assisted Living Residents: A Photo-Elicitation Study”, Geriatric Nursing, Vol. 41 No. 6, pp. 812-821.

Marek, K. D. and Rantz, M. J. (2000), “Aging in Place: A New Model for Long-Term Care”, Nursing Administration Quarterly, Vol. 24 No. 3, pp. 1-11.

Milligan, C., Bingley, A. and Gatrell, A. (2005), "Digging Deep: Using Diary Techniques to Explore the Place of Health and Well-Being Amongst Older People", Social Science and Medicine, Vol. 61 No. 9, pp. 1882-1892.

Morrison, C. and Dearden, A. (2013), "Beyond Tokenistic Participation: Using Representational Artefacts to Enable Meaningful Public Participation in Health Service Design”, Health Policy, Vol. 112 No. 3, pp. 179-186.

Rosner, T. T., Namazi, K. H. and Wykle, M. L. (1992), "Health Diaries and Interviews: Consistency in Reporting by Older Adults", Research on Aging, Vol. 14 No. 2, pp. 248-266.

Sormunen, E., Nevala, N. and Sipila, S. (2014), "Critical Factors in Opening Pharmaceutical Packages: A Usability Study Among Healthcare Workers, Women with Rheumatoid Arthritis and Elderly Women", Packaging Technology and Science, Vol. 27 No. 7, pp. 559-576.

Ward, J., Buckle, P. and Clarkson, P. J. (2010), "Designing Packaging to Support the Safe Use of Medicines at Home", Applied Ergonomics, Vol. 41 No. 5, pp. 682-694.

Wilkinson, C. R. and Angeli, A. D. (2014), “Applying User Centred and Participatory Design Approaches to Commercial Product Development”, Design Studies, Vol. 35 No. 6, pp. 614-631.

Visser, F. S., Lugt, R. V. D. and Stappers, P. J. (2007), "Sharing User Experiences in the Product Innovation Process: Participatory Design Needs Participatory Communication", Creativity and Innovation Management, Vol. 16 No. 1, pp. 35-45.

World Health Organization (WHO). (2012), 10 Facts on Ageing and the Lifecourse. [online]. Available at: https://www.who.int/features/factfiles/ageing/ageing_facts/en/ (accessed November 2, 2020).

Xie, B., Druin, A, Fails, J., Massey, S., Golub, E., Franckel, S. and Schneider, K. (2012), "Connecting Generations: Developing Co-Design Methods for Older Adults and Children”, Behaviour \& Information Technology, Vol. 31 No. 4, pp. 413-423.

Zimmerman, D. H. and Wieder, D. L. (1977), “The Diary Interview Method”, Urban Life, Vol. 5 No. 4 , pp. $479-499$. 